\title{
Breastfeeding in children under 2 years old and household food and nutrition security status
}

\author{
Gisele P. Gomes, ${ }^{1}$ Muriel B. Gubert ${ }^{2}$
}

\begin{abstract}
Objective: To investigate the association between household food and nutrition security status and breastfeeding among children under 2 years old.

Methods: Data were analyzed from 1,635 children under 2 years old who had participated in the Brazilian National Demographic and Health Census in 2006. The outcome (breastfeeding) was evaluated according to data on the children's food intake on the day before the interview and food insecurity was assessed using the Brazilian Food Insecurity Scale.

Results: Approximately $58 \%$ of children were breastfeeding and $47 \%$ were living in households with food insecurity. There was an association between breastfeeding and households in a state of food insecurity, but only for children older than 12 months. In this age group, breastfeeding prevalence was higher (41\%) among children living in households with food and nutrition insecurity than those who lived in households considered secure (29\%). There were no associations between food insecurity and breastfeeding in the first year of life or early introduction of foods other than breastmilk.
\end{abstract}

Conclusion: Food insecurity is associated with a higher prevalence of breastfeeding in the second year of life.

J Pediatr (Rio J). 2012;88(3):279-82: Breastfeeding, food insecurity, infant feeding.

\section{Introduction}

When breastfeeding is practiced in accordance with the recommendations for each age group it has a positive impact on the nutritional status, health and development of children. ${ }^{1-3}$ The practice can also protect infants who live in households where there is insecurity with relation to food and nutrition; since, in conditions where access to food of adequate quality is restricted, ${ }^{4}$ breastmilk (whether as exclusive source of nutrition or supplemented with complementary feeding) costs families very little. ${ }^{3}$

The prevalence rates of breastfeeding are rising in Brazil, 5 but no studies have been conducted here that directly analyze the relationship between household food and nutrition insecurity and breastfeeding. Working from the hypothesis that breastfeeding could be more prevalent among children in food insecure households, in view of its protective properties in such situations, the objective of this study was to investigate the association between breastfeeding of children under 2 years old and the food and nutrition security status of the households in which they live.

\section{Methodology}

The data used here were collected as part of the National Demographic and Health Census (PNDS - Pesquisa Nacional de Demografia e Saúde) (PNDS), which was conducted

1. Nutritionist. Universidade de Brasília (UnB), Brasília, DF, Brazil.

2. Nutritionist, PhD in Health Sciences. Adjunct professor, Departamento de Nutrição, UnB, Brasília, DF, Brazil.

No conflicts of interest declared concerning the publication of this article.

Suggested citation: Gomes GP, Gubert MB. Breastfeeding in children under 2 years old and household food and nutrition security status. J Pediatr (Rio J). 2012;88(3):279-82.

Manuscript submitted Mar 31 2011, accepted for publication Dec 92011.

http://dx.doi.org/10.2223/JPED.2173 
in 2006. The census design was cross-sectional, with households as the units of a complex probabilistic sample frame with national representativeness, and the survey covered the female population resident in private households located in common sectors of both urban and rural areas in all five Brazilian macro-regions. ${ }^{6}$

The PNDS sample comprised 14,617 eligible women aged 15 to 49.6 For this study, data was extracted on the 1,635 of these women's children who were less than 2 years old at the time of data collection. Since this was a householdbased survey with complex probabilistic sampling, expansion factors were used to guarantee national representativeness, meaning that each child's data has its own sampling weight. This strategy recreates the proportions of the Brazilian population in the sample.

The data analyzed here were sociodemographic variables and the children's dietary intake on the day before their mothers were interviewed, including details on breastmilk intake. Children were defined as breastfeeding if they were being given breastmilk at the time of data collection. The category "other foods" refers to any type of food other than breastmilk (solid or liquid and including water, teas and non-breastmilk milks). Other foods were considered to have been introduced prematurely if given before the child reached 6 months.

Household food insecurity was measured using the Brazilian Food Insecurity Scale (BFIS). ${ }^{7}$ The BFIS comprises 15 items that investigate different degrees of experience of food insecurity and hunger and produces a household food insecurity score based on the number of affirmative answers. The scale classifies insecurity into three categories (mild, moderate and severe), which, for the purposes of this study, were collapsed into a single category of "food insecurity". Households are therefore classified dichotomously as having food security or food insecurity.

Statistical analysis was conducted with the aid of the Statistical Package for the Social Sciences (SPSS) for expanded samples. Prevalence rates were calculated and linear tendencies of associations between variables were assessed using the chi-square test, to a significance level of $5 \%(p<0.05)$.

The PNDS was approved by the Research Ethics Committee at the Centro de Referência e Treinamento DST/AIDS, belonging to the São Paulo State Health Department, under protocol number 029/05.8.

\section{Results}

Table 1 lists the characteristics of the sample. It will be observed that just $57.5 \%$ of children under 2 were breastfeeding in Brazil. Furthermore, $47.2 \%$ of the children surveyed were living in households in a state of food and nutrition insecurity.
An association between breastfeeding and households in a state of food insecurity was only detected in children over 12 months (Table 2 ). In this age group, breastfeeding prevalence was higher among children living in households with food and nutrition insecurity (41.3\%) than among those living in households considered secure (29.2\%). There were no associations between food insecurity and breastfeeding during the first year of life or premature introduction of other foods. It is notable that $70.3 \%$ of infants under 6 months old from households in a state of food insecurity were already being given foods other than breastmilk.

\section{Discussion}

Almost half of the children studied (47.2\%) were living in a state of food insecurity. This is a serious situation because food insecurity in infancy can cause growth and development deficits and increase susceptibility to diseases and infections. ${ }^{9,10}$ In such cases, breastfeeding is crucial to maintaining the minimum intake of necessary nutrients and for protection against the diseases of this stage of life.

In this study, it was found that breastfeeding was more prevalent among children aged 12 to 24 months living in households considered insecure from the perspective of food and nutrition, when compared with those living in secure households $(p<0.05)$. This could indicate that breastfeeding is a protective strategy for infants in adverse conditions. The same tendency was observed among children under 12 months old living in a state of food insecurity, although to a lesser degree and without statistical significance. For children from households in food insecurity, breastfeeding is of special importance since when access to food is restricted the nutritional and immunological characteristics of breastmilk can protect children from an unhealthy diet or from the consequences of continued nutritional privation. ${ }^{11}$

The association between breastfeeding and improving the adverse conditions caused by household food insecurity was shown in a study conducted in the United States with immigrant mothers other countries. Researchers observed an association between breastfeeding and better child health conditions in households in a state of food insecurity. ${ }^{11}$

While breastfeeding is to be encouraged in cases of household food insecurity, it should be remembered that maintenance of exclusive breastfeeding beyond 6 months of age, which is sometimes observed in cases of food insecurity because of a lack of food, can have a negative impact on child health. ${ }^{12}$

Although premature (before 6 months) introduction of foods other than breastmilk was not significantly 
more prevalent in households with food insecurity in this study, the practice itself is defined as a risk to infant nutrition and health. 1,3,13 Consumption of other foods can compromise breastfeeding, involve microbiological risks and/or increase susceptibility to the consequences of the nutritional privation that is inherent to the conditions in which such children live. $3,4,10$ An earlier study showed that premature introduction of other foods into the infant diet is more common in families living in pockets of poverty, which further increases the risk to children because of the lack of access to adequate foods. ${ }^{14}$

In conclusion, this study has shown that breastfeeding was more prevalent during the second year of life among children living in households in a state of food insecurity, which could indicate that this is a protective strategy against the adverse condition of food restriction or privation in which these children live. Food insecurity did not explain differences in premature introduction of other foods.

Table 1 - Sociodemographic characteristics of the sample

\begin{tabular}{|c|c|c|}
\hline Variables & $\% *$ & $\mathbf{n}^{+}$ \\
\hline \multicolumn{3}{|l|}{ Characteristics of infants } \\
\hline \multicolumn{3}{|l|}{ Region } \\
\hline North & 10.8 & 379 \\
\hline Northeast & 28.0 & 325 \\
\hline Mid-west & 8.0 & 339 \\
\hline Southeast & 41.7 & 305 \\
\hline South & 11.5 & 287 \\
\hline Total & 100.0 & 1,635 \\
\hline \multicolumn{3}{|l|}{ Age } \\
\hline 0-11 months & 50.3 & 783 \\
\hline $12-24$ months & 49.7 & 852 \\
\hline Total & 100.0 & 1,635 \\
\hline \multicolumn{3}{|l|}{ Characteristics of mothers } \\
\hline \multicolumn{3}{|c|}{ Educational level (years in education) } \\
\hline $0-4$ & 39.1 & 749 \\
\hline $5-8$ & 25.6 & 393 \\
\hline 9 or more & 35.4 & 474 \\
\hline Total & 100.0 & 1,616 \\
\hline \multicolumn{3}{|l|}{ Employment (paid) } \\
\hline Employed & 6.0 & 61 \\
\hline Unemployed & 94.0 & 777 \\
\hline Total & 100.0 & 838 \\
\hline \multicolumn{3}{|l|}{ Marital status } \\
\hline Married & 84.5 & 1,017 \\
\hline Other marital status & 15.5 & 175 \\
\hline Total & 100.0 & 1,192 \\
\hline \multicolumn{3}{|c|}{ Characteristics of households } \\
\hline \multicolumn{3}{|c|}{ Food and nutrition security } \\
\hline Security & 52.8 & 844 \\
\hline Insecurity & 47.2 & 791 \\
\hline Total & 100.0 & 1,635 \\
\hline
\end{tabular}

National Demographic and Health Census (PNDS - Pesquisa Nacional de Demografia e Saúde), 2006.

* Percentages calculated after expansion of the sample to the Brazilian population, guaranteeing national representativeness.

† The figures in the " $n$ " column represent valid responses. The value of " $n$ " is the number of individuals in the sample, before expansion for the whole population. 
Table 2 - Distributions of children breastfeeding and dietary intakes by age group and household food and nutrition security status

\section{Age group/ food and} nutrition security status

\section{Feeding}

Entire sample (\%)

12-24 months

Security

Insecurity

Entire sample (\%)

0-6 months

Security

Insecurity

Entire sample (\%)

0-12 months

Security

Insecurity

Entire sample (\%)
Breastfeeding (\%)

76.7

82.7

79.3

0.22

$<0.05$

29.2

41.3

35.4

Given other foods on day before interview (\%)

0.30

60.9

70.3

65.0

Given non-breastmilk milks (\%)

0.71

\section{References}

1. World Health Organization. Global strategy for infant and young child feeding. Geneva: World Health Organization; 2003.

2. WHO, UNICEF, USAID, AED, UCDAVIS, IFPRI. Indicators for assessing infant and young child feeding practices: conclusions of consensus meeting held 6-8 November 2007 in Washington D.C., USA. Geneva: World Health Organization; 2008.

3. Brasil. Ministério da Saúde. Secretaria de Atenção à Saúde. Departamento de Atenção Básica. Saúde da criança: nutrição infantil: aleitamento materno e alimentação complementar. Brasília: Editora do Ministério da Saúde, 2009

4. Bickel G, Nord M, Price C, Hamilton W, Cook J. Measuring food security in the United States: guide to measuring household food security. Alexandria: Office of Analysis, Nutrition, and Evaluation, U.S. Department of Agriculture; 2000.

5. Venancio SI, Escuder MM, Saldiva SR, Giugliani ER. Breastfeeding practice in the Brazilian capital cities and the Federal District: current status and advances. J Pediatr (Rio J). 2010;86: 317-24.

6. Brasil. Ministério da Saúde. Pesquisa Nacional de Demografia e Saúde da Criança e da Mulher - PNDS 2006: dimensões do processo reprodutivo e da saúde da criança. Brasília: Ministério da Saúde; 2009.

7. Instituto Brasileiro de Geografia e Estatística (IBGE). Pesquisa Nacional por Amostra de Domicílios: segurança alimentar 2004. Rio de Janeiro: IBGE; 2006.

8. Brasil. Ministério da Saúde. Pesquisa Nacional de Demografia e Saúde da Criança e da Mulher - PNDS 2006: aspectos metodológicos. Brasília: Ministério da Saúde; 2008.
9. Cook JT, Frank DA, Berkowitz C, Black MM, Casey PH, Cutts DB, et al. Food insecurity is associated with adverse health outcomes among human infants and toddlers. J Nutr. 2004;134:1432-8.

10. Saha KK, Frongillo EA, Alam DS, Arifeen SE, Persson LA, Rasmussen KM. Household food security is associated with infant feeding practices in rural Bangladesh. J Nutr. 2008;138:1383-90.

11. Neault NB, Frank DA, Merewood A, Philipp B, Levenson S, Cook JT, et al. Breastfeeding and health outcomes among citizen infants of immigrant mothers. J Am Diet Assoc. 2007;107:2077-86.

12. Hong R, Banta JE, Betancourt JA. Relationship between household wealth inequality and chronic childhood under-nutrition in Bangladesh. Int J Equity Health. 2006;5:15.

13. Monte CM, Giugliani ER. Recommendations for the complementary feeding of the breastfed child. J Pediatr (Rio J). 2004;80:S131-41.

14. Silveira FJ, Lamounier JA. Prevalência do aleitamento materno e práticas de alimentação complementar em crianças com até 24 meses de idade na região do Alto Jequitinhonha, Minas Gerais. Rev Nutr. 2004;17:437-47.

Correspondence:

Gisele Pereira Gomes

QSA 16 - casa 28

CEP 72015-160 - Taguatinga, Distrito Federal - Brazil

Tel.: +55 (61) 3352.9472, +55 (61) 9666.2445

E-mail: gisele.gpg@gmail.com 